\title{
ANALITIČNI PRISTOP K NAČRTOVANJU VIROV IN SPREJEMANJU ODLOČITEV V OBRAMBNEM SISTEMU
}

\section{ANALYTICAL APPROACH TO RESOURCE PLANNING AND DECISION MAKING IN THE DEFENCE SYSTEM}

Povzetek V prispevku opredeljujemo ožji koncept načrtovanja obrambnih virov (poudarek je na finančnih virih), ki temelji na dejanjih in rezultatih ter presega odločitve le na podlagi intuicije za doseganje boljših rezultatov pri odločanju, razporejanju in načrtovanju vojaških sredstev ter zmogljivosti. Viri v sodobnih vojaških organizacijah so omejeni in prav njihova načrtna/namenska dodelitev in racionalna izraba oziroma poraba predstavlja velik izziv sodobnega načrtovanja. Za doseganje optimalnih rezultatov je zelo pomembno razumevanje in poznavanje obstoječih virov, njihovo razporejanje in upravljanje znotraj vojaške organizacije. Nepravilno razporejeni viri prinašajo dodatne negativne posledice, kot so višji stroški, tehnološki zaostanek in zmanjševanje možnosti reševanja življenj. Z analitičnim pristopom upravljanja se oblikuje temeljna podlaga za raziskovanje vzrokov, procesov in pojavov odstopanj od načrtovanja virov skozi kratkoročna, srednjeročna in dolgoročna obdobja obrambnega načrtovanja. Predstavljena je metodologija procesa obrambnega načrtovanja, ki je osredotočena predvsem na kvantitativne pristope kot komplementarni del kvalitativnemu segmentu raziskovanja.

Ključne Upravljanje virov, intuicija, analiza stroškov in koristi, ekonomska analiza, besede matematični analitični modeli, proces odločanja.

Abstract In the article, we define a narrow concept of defence expenditure planning (with the emphasis on financial resources), which is based on the acts and results and exceeds intuition-based decisions to achieve better results in decision making, allocation and planning of military assets and capabilities. Resources in modern military organizations are limited and it is their planned or eligible allocation and rational use and consumption that represent a major challenge in modern planning. In order to achieve optimum results, understanding and awareness of the existing resources, their allocation and management within a military organization are 
crucial. Incorrectly allocated resources bring additional adverse consequences, such as higher costs, technological backlog and reduced possibility of saving lives. An analytical management approach creates the basis for exploring the causes, processes and phenomena of deviations from resource planning through short-term, mediumterm and long-term defence planning periods. The article presents the methodology of the defence planning process, which is mainly focused on quantitative approaches as a complementary part of the qualitative research segment.

Key words Resource management, intuition, cost-benefit analysis, economic analysis, mathematical analytical models, decision-making process.

Uvod Uspešnost poslovanja je odvisna od kakovostnega odločanja v celotnem procesu poslovanja, od načrtovanja pa vse do izvedbe. Temelj kakovostnega odločanja je analiza procesov poslovanja, organizacije in okolja, v katerem smo (grožnje, tveganja in priložnosti). Predstavljene so možnosti analitičnega pristopa pri načrtovanju virov in sprejemanju odločitev v obrambnem sistemu, ki so po našem mnenju v današnjih razmerah v kombinaciji oziroma ustreznem ravnovesju pri uporabi tako kvantitativnih kot tudi kvalitativnih pristopov, pri čemer sta predvsem pomembni sposobnost in hitrost prilagajanja na nenehne spremembe.

$\mathrm{V}$ prispevku so predstavljeni in analizirani primeri analiz, s katerimi se bomo predvsem osredotočili na spremembe načrtovanja, ki so po našem mnenju nujne, če želimo dosegati bolj gospodarne rešitve z zelo omejenimi viri in hkrati zagotavljati transparentnost in sledljivost odločitev o razporejanju resursov. Osnovni ekonomski izziv Republike Slovenije na področju obrambnega načrtovanja je kompromis med ambicijami RS, ki določajo cilje zmogljivosti, in omejenimi viri, s katerimi se spoprijemamo pri delovanju in načrtovanju.

V vojaški organizaciji je strokovnost najpomembnejša za vsakega voditelja in je le eden izmed elementov večopravilnosti (multivariantnosti). Na splošno v družbi se na primer psihoterapevti in celo kirurgi zavedajo omejitev pri svoji strokovnosti, saj se naučijo in prepoznavajo določene vzorce pri pacientih, vendar se nikoli ne ponavljajo na enak način. Čeprav gre za ponovitve, je vsak primer poseben in ga je treba obravnavati glede na konkretne okoliščine, kar pa ne velja za vojaško organizacijo.

Razlogi o tem, zakaj se moramo v procesu odločanja zanašati predvsem na ugotovitve iz analiz in precej manj na intuicijo oziroma človeški instinkt, temeljijo na spoznanjih in znanstvenih dokazih, da človek večino svojih odločitev praviloma ne sprejema na racionalni podlagi oziroma na podlagi razumskega premisleka, ampak se večinoma odziva na podlagi svojih čustev. To je tudi eden glavnih razlogov za pojavljanje sistematičnih napak v procesu odločanja in za omejeno ali limitirano sposobnost oziroma zmožnost interpretacije problema ali pojava. Proces pridobivanja informacij, ki poteka od vizualnega dela (oči) do posameznih delov za obdelavo videnega ter 
nalaganje v spomin, je pri vsakem človeku drugačen. Zanašanje le na intuicijo, izkušnje in presojo v procesu odločanja dokazano vodi v površne ocene stanja, na podlagi katerih se posledično sprejemajo pomanjkljive ali celo napačne odločitve. Do večje zlorabe intuicije $\mathrm{v}$ procesu odločanja, seveda to velja samo takrat, ko govorimo o razporejanju finančnih virov, prihaja na strateški ravni odločanja.

\section{ANALITIČNI PRISTOP K NAČRTOVANJU/RAZPOREJANJU OBRAMBNIH VIROV}

Ker so finančni viri v obrambnem sistemu določeni in omejeni in so lahko različno uporabljeni, smo kot dobri »gospodarji« vedno prisiljeni izbirati med različnimi bolj ali manj ekonomičnimi rešitvami. Podlaga za boljše odločanje je skoraj vedno analitični pristop, kar pomeni reševanje kompleksnih problemov z različnimi statističnimi metodami in orodji za odkrivanje pomanjkljivosti. V tem prispevku se osredotočamo le na analitične pristope k reševanju kompleksnih obrambnih načrtov. Analitičnost pomeni razdelitev kompleksnega problema na manjše razumljive enote. Za večino odločitev pri razporejanju virov je potreben čas.

Poznamo dva tipa ekonomskih analiz: mikroekonomija in makroekonomija. Mikroekonomija preučuje različne možnosti odločanja posameznikov, gospodinjstev, podjetij in vlad glede učinkov na trg za določeno dobrino ali storitev, medtem ko makroekonomija preučuje nacionalne ekonomije kot celote (Quade, idr., 2014, str. 12). V obrambnem sistemu moramo upoštevati oba tipa ekonomske analize, in sicer glede na vrsto načrtovanja, ki je kratkoročno, srednjeročno in dolgoročno, in upravljanja finančnih virov.

Prednost analitičnega pristopa k problematiki v načrtovanju je, da lahko strokovno osebje preuči stanje in poda svoje mnenje ter se zagotovi transparentnost/sledljivost odločitev. Tako se lahko posamezne predpostavke odločevalcev spreminjajo pod vplivom/na pobudo drugih strokovnih nosilcev, če se to izkaže v določenih situacijah kot boljše uravnavanje virov (modeliranje procesov, ki vključujejo različne vrednosti spremenljivk posameznih parametrov). SV/MO RS na svojem razvojnem področju uporablja analitično metodo DOTMPLFI ${ }^{1}$, ki je sorodna analitični metodologiji $\mathrm{GOAMP}^{2}$ pri finančnem načrtovanju in je standard razporejanja virov v obrambnem sistemu (povzeto po izročkih DRMI ${ }^{3}$ ).

Namen analitične metodologije GOAMP (v uporabi pri finančnem načrtovanju $\mathrm{v}$ obrambnih silah ZDA) najprej predstavlja orodje za odločitev o tem, katere cilje

\footnotetext{
DOTMPLF-I (Doctrine, Organization, Training, Material, Personnel, Leadership, Facilities and Interoperability) - Doktrina, organizacija, usposabljanje, oprema, kadri, voditeljstvo, objekti in interoperabilnost. Tak pristop se v zavezništvu uporablja pri razvoju pomembnih elementov zmogljivosti (Joint Analysis Handbook, 2016, str. 44).

2 GOAMP (Goal, Objectives, Alternatives, Model and Preferences) - Namen, cilj, možnosti, model in prednosti različnih alternativ (povzeto po izročkih DRMI).

3 Defense Resource Management Institute - Naval Postgraduate School, Monterey, CA, USA.
} 
bomo dosegli in kdaj jih bomo dosegli. V naslednjem koraku se je treba odločiti, kako sledimo zastavljenim ciljem in kakšne so rešitve, možnosti ter pravila za doseganje teh ciljev. V predzadnjem koraku je potrebno še matematično modeliranje za preverjanje in merjenje učinkov različnih alternativ. V zadnjem koraku se ugotavlja, kakšne so prednosti alternativ, za katere se odločamo. Usklajenost/sinhroniziranost obeh navedenih metodologij postaja nujna potreba ali celo že standard v organizaciji Nata (povzeto po izročkih DRMI).

Za upravljanje virov moramo razumeti osnovne procese, ki so povezani z analitičnim pristopom do reševanja finančnega načrtovanja. Procesi se začnejo in končajo na treh ravneh:

- proces obrambnega strateškega načrtovanja s sistemskimi analizami (nosilca Direktorat za obrambno politiko in Generalštab SV);

- proces implementacije in razvoj programov s programsko analizo (nosilci Direktorat za Logistiko, Direktorat za obrambno politiko, Služba za finance in Generalštab SV);

- operativni proces z operativnimi analizami (raven Poveljstva sil SV).

Vsi procesi morajo stremeti k učinkovitosti in ekonomičnosti. Model za obvladovanje procesov, ki ga uporablja DRMI, in je prilagojen slovenskemu obrambnemu resorju, je grafično prikazan na sliki 1 .

Kot je razvidno iz grafičnega prikaza upravljanja virov v vojaški organizaciji, se uporabljajo najprej sistemske analize, nato programske analize in na koncu še operativne specifične analize z raznovrstnimi vplivi od zunaj in znotraj organizacije. Informacije o upravljanju finančnih virov prehajajo od zunaj navznoter in obratno. Pri obrambnem načrtovanju virov gre za t. i. pristop Top-down. Strateški organ (Nacionalni varnostni organ) najprej izvede postopke vojaškega strateškega načrtovanja, opravi sistemske analize, pregleda oziroma izpopolni načrte strukture vojaške organizacije in upošteva splošne omejitve. Srednji menedžment izvaja proces implementiranja in na koncu izvajalci opravijo še operativni proces obrambnega načrtovanja virov. Nenehno je treba aktivno spremljati tudi različne vplive (politične, zgodovinske, ekonomske, tehnološke), alternative, grožnje in omejitve. Ekonomski vplivi so povezani z omejitvami, ki izhajajo iz proračuna, politični pa iz različnih groženj in ravni sprejemljivega tveganja.

\subsection{Preseganje intuicije (vrednotenje tehtnosti)}

Ljudje večinoma nismo racionalni pri sprejemanju svojih odločitev, zato smo pri odločanju nagnjeni k sistematičnim napakam. Zanašanje na izkušnje, intuicijo in presojo v procesu odločanja lahko pripelje do zelo slabih rešitev in rezultatov, zato je treba, da bi se ognili negativnim posledicam takega odločanja, uporabiti modele in se opirati na rezultate analiz. Intuicija je oblika obdelave podatkov v več korakih, ki se razlikuje od racionalnih ali analitičnih procesov. Intuicija je sicer pomembna sestavina odločanja, vendar ostajajo prevelika tveganja, ki jih lahko zmanjšujemo z mnenji različnih strokovnjakov in s kakovostnimi analizami. 
Slika 1:

Proces upravljanja virov v vojaški organizaciji (povzeto po izročkih DRMI)

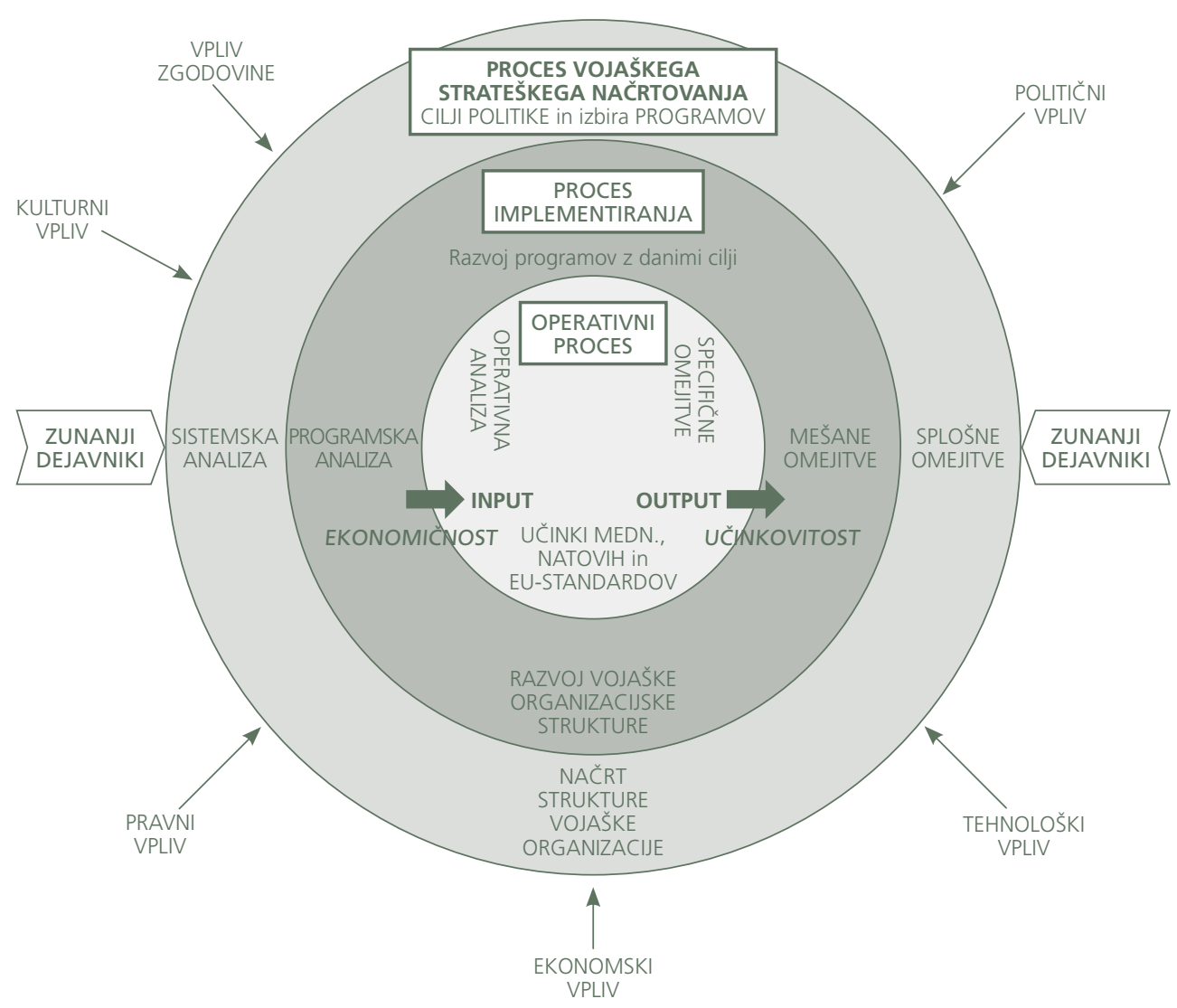

Preveliko zanašanje na svoje sposobnosti (znanje in tudi položaj (moč)) pri odločanju pomeni večje tveganje in negativne stroškovne posledice, tudi za vojaške organizacije. Navadno je samozavesten optimist zelo cenjen v organizacijah in prav zato prihaja še do večjih zmot (Kahneman, 2011, str. 253-254). Kahneman v načinu razmišljanja strukturira dva sistema:

Tabela 1:

Dva načina

odločanja po

Kahnemanu

(2011)

\begin{tabular}{|l|l|}
\hline NAČIN 1 - HITER & NAČIN 2 - POČASEN \\
\hline Avtomatično razmišljanje daje občutek lahkotnosti. & Zahteva koncentracijo in napor. \\
\hline Identifikacija s čustvi. & Identificiran z logiko. \\
\hline Podzavestno ravnanje. & Zavestno in opisljivo. \\
\hline Stereotipno. & Se uporablja manj pogosto. \\
\hline Vedno ima odgovor. & Kalkuliranje, včasih v zadregi za odgovor. \\
\hline Intuitivno. & Analitično. \\
\hline
\end{tabular}


Pri reševanju problemov že s površnim pregledom lahko ugotovimo, ali gre za enostaven ali zahteven problem. Glede na to se odločamo za primerno tehniko odločanja, torej hitro ali počasno. Pri hitrem odločanju se večinoma zanašamo na lastno intuicijo in izkušnje, vendar je ta pristop ustrezen le takrat, ko gre za (1) prepoznavanje določenih vzorcev, (2) uveljavljanje enkratnih odločitev, ki so samo v določenem/trenutnem časovnem okviru in razmerah sprejemljive, (3) imamo večji/obsežnejši strokovni nadzor nad problematiko in (4) vsi dejavniki niso prepoznavni. Gre za preproste oziroma nezahtevne probleme, ki so omejeni s časom, ki nam je na voljo, ter ne zahtevajo poglobitve na strokovnem področju.

Tehnika počasnega odločanja se uporablja v situacijah, v katerih se zahtevajo (1) večja konsistentnost, (2) višja stopnja natančnosti, (3) možnost avtomatizacije (uporaba algoritma), (4) sodelovanje ekspertov različnih področij, transparentnost in razpoložljivost ter (6) jasen opis/oris postopkov odločanja.

Zanesljivo lahko trdimo, da je kognitivna sposobnost oziroma zmožnost vsakega človeka omejena in nezanesljiva, čeprav lahko tudi ta segment z uporabo ustreznih tehnik izboljšamo, nikakor pa povsem odpravimo. To je poglaviten razlog, da je v procesu sprejemanja odločitev najpomembnejša, seveda poleg zavedanja vseh naštetih ali opisanih omejitev, uporaba veljavnih in v preteklosti uveljavljenih kvalitativnih in kvantitativnih metod (analitičnih orodij) in modelov ter tako priti do merljivih, zanesljivih, natančnih, preverljivih in objektivnih spoznanj ali ugotovitev/rezultatov.

$\mathrm{Na}$ področju intuicije in pretirane samozavesti je treba nadaljevati raziskave, ki vplivajo na odločitve v obrambnem sistemu. Razlike med intuicijo in presojo so pomemben dejavnik odločanja, ki so prikazane v štirih načinih analitičnega odločanja prek sistemskih analiz, stroškovnih analiz, načinov merjenja učinkovitosti in vrednotenja.

\subsection{Ekonomičen način razmišljanja (Where do we spend the money?)}

Vojaški načrtovalski in razvojni oddelki nenehno povečujejo zahteve po virih za 10-25 odstotkov več, kot je omejen proračun in malokdaj prikazujejo dvojno vrednost (Quade, et al., 2014: 35-36). Zato je zelo priporočljivo, da se pri načinu razmišljanja osredotočamo na model (metodologija GOAMP), s katerim si lahko odgovorimo na osnovna vprašanja pri upravljanju finančnih virov. Fizični model obrambnega ekonomičnega razmišljanja je proces razmišljanja o glavnih kategorijah, ki so učinkovitost, stroški, razpoložljivost in tveganja.

Vse štiri kategorije $\mathrm{v}$ tem modelu moramo preveriti $\mathrm{z}$ analizami in tehnikami predvidevanj. To je podlaga za predinvesticijsko zasnovo za različne projekte, investicijsko dokumentacijo in kratkoročno, srednjeročno in dolgoročno načrtovanje. Slednji model bi bil primeren na področju obrambnih načrtovanj, saj le tako lahko poleg izboljšanja procesov zmanjšujemo ali blažimo napačne odločitve in posledično tudi tveganja. 
Slika 2:

Model procesa ekonomičnega razmišljanja, ki ga lahko uporabimo tudi v obrambnem sistemu (lasten prikaz)

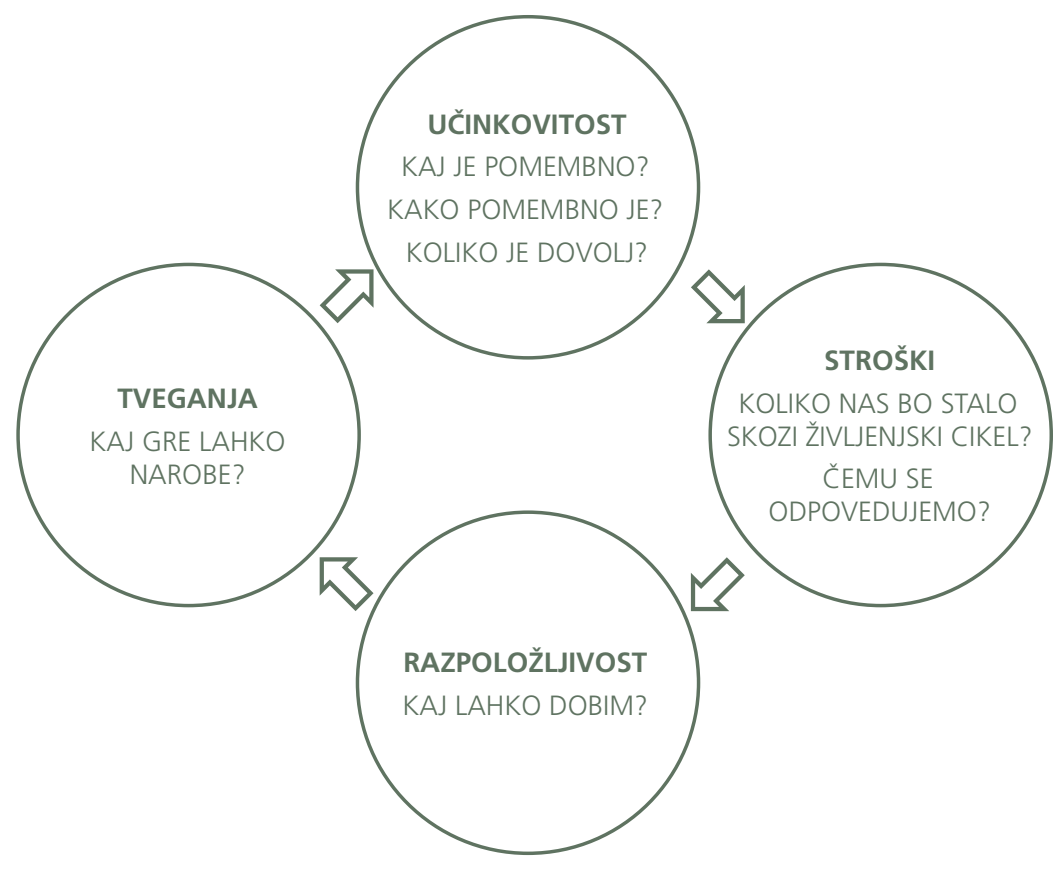

Prvi primer sodobnega ekonomičnega razmišljanja ${ }^{4}$ na obrambnem področju v Evropi je bil pred leti, ko sta se francoski in nemški proizvajalec tankov (Nexter in KraussMaffei Wegmann) združila (Mehta, 2016). Najnovejši primer je namen norveške in nemške vlade za nabavo enakih podmornic. To prikazuje, da nabava združenih zmogljivosti ne zmanjšuje le stroškov nabave (do 30 \% vrednosti), temveč tudi stroške življenjskega cikla nekega oborožitvenega sistema. Stroški vzdrževanja od celotne cene oborožitvenega sistema skozi življenjski cikel so 30-60 \% in pomenijo pomemben stroškovni element, ki ga je treba z združevanjem zmanjševati (Sintern, 2017, str. 31-32). Ugotavljamo, da združevanje razvoja in uporabe oborožitvenih sistemov v zavezniškem okolju zagotavlja interoperabilnost, hkrati pa je to najbolj racionalen in najcenejši način. Tradicionalen način samostojnega nastopanja na tržišču kaže, da je ta pristop najdražji pristop.

\subsection{Analiza stroškov in koristi (cost-benefit analysis) pri razporejanju obrambnih virov}

Analiza stroškov in koristi je sistematizacija projektov/postopkov, s katero se ugotavljajo vrednosti posameznih sistemov in orožij. S primerjavo različnih alternativ (različic) iščemo optimalne rešitve in še druge manj optimalne v nekem vrstnem redu (Melese, idr., 2015, str. 1). Osnovni princip analize stroškov in koristi pri omejenih

Sodobnih primerov je še nekaj, kot so načrtovano novo združeno francosko-nemško bojno letalo, Euro-dron, modernizacija bojnega helikopterja Tiger, skupno delovanje v kibernetskem bojevanju (predvsem v smislu izmenjave in dopolnjevanja kadrov). 
virih je, da so koristi večje od stroškov. Stroški in koristi se težje preračunavajo in izključevanje stroškov pomeni tudi izključevanje koristi.

Največji izziv obrambne stroškovne analize $\mathrm{v}$ prihodnosti je razvoj konceptov in tehnik v razmerah negotovosti. $\mathrm{V}$ nacionalnih obrambnih problemih načrtovanja se navadno pojavi kombinacija štirih alternativ:

1. predlaganje nove zmogljivosti v prihodnosti - npr. novo orožje ali sistem,

2. predlog modifikacije trenutne zmogljivosti,

3. predlog ukinitve trenutne zmogljivosti,

4. predlog združevanja vseh treh skupaj (1-3) - to je struktura obrambnih sil v prihodnosti (Quade, idr., 2014, str. 221). Od tu izvira neracionalnost pri odločanju za zmogljivosti, ki se v praksi prevečkrat uporablja, zato se lahko stroški neracionalno povečujejo na račun koristi, če ne izberemo ustrezne alternative. Če prekršimo načelo ekonomičnosti, so vsi nadaljnji koraki in postopki neracionalni ter postajajo stroškovno nevzdržni.

Z identifikacijo posameznih faz analize življenjskega cikla novega oborožitvenega sistema (MLCA - Military Life Cycle Assessment) $)^{5}$ se oblikuje okolje za stroškovno analizo. Stroškovna analiza se na podlagi vložkov (inputov) v vojaških organizacijah opredeli na treh kategorijah:

1. Stroški raziskav in razvoja (R\&D) - viri, potrebni za razvoj nove zmogljivosti za operativno uporabo:

a. stroški predhodnega oblikovanja in inženiring,

b. stroški izdelovanja opreme za izvedbo preverjanj (prototip),

c. stroški operativnega testiranja.

2. Investicijski stroški - enkratni nabavni stroški, ki so potrebni za vpeljavo zmogljivosti v operativni inventar:

a. stroški glavne opreme,

b. stroški inventarja,

c. stroški začetnih usposabljanj,

č. stroški infrastrukture.

3. Operativni stroški - vsakoletni ponavljajoči se operativni stroški za operativno delovanje in vzdrževanje oborožitvenega sistema:

a. stroški opreme in vzdrževanje infrastrukture,

b. vzdrževanje opreme,

c. plače in stroški dela,

č. nadomestna usposabljanja,

d. goriva, maziva in pogonska sredstva (Quade idr., 2014, str. 213-215).

»Od zibelke do groba». 
Vse tri kategorije predstavljajo uporabno standardizirano metodologijo pri načrtovanju, sledenju in obvladovanju različnih finančnih postavk, saj lahko le tako obvladujemo finančne tokove in njihove učinke.

Med tveganji in analizo stroškov in koristi v vojaški organizaciji obstaja povezava. Pri odločanju moramo vedno premisliti, da čim bolj povečamo koristi in da so te vedno večje od 0 (Stewart in Mueller, 2013, str. 895).

\section{UČINKOVITOST V OBRAMBNIH ODLOČITVAH (COST EFFECTIVENESS ANALYSIS)}

Mikuž in Šavc (2011, str. 66) navajata, da »bodo oborožene sile vse bolj integrirane, saj majhne in srednje države ne morejo vzdrževati celovitih konvencionalnih zmogljivosti. Tehnologija narekuje hitrost in investicije se podvojijo na 10 do 20 let, zato je treba zmanjšati številčnost, a povečati kakovost in učinkovitost.« Da bi sledenje dosegli pri obrambnih odločitvah, je neizogibna uporaba trenutnih ekonomskih analiz in kvantitativnih metod.

\subsection{Elementi ekonomske analize}

Z vojaškim načrtovanjem in izvajanjem ekonomske analize se ukvarjajo t. i. proračunski programerji v vojaških organizacijah, ki so odgovorni za petletno programiranje vojaškega proračuna $\mathrm{v}$ obdobju od dveh let naprej. Proračunski programer je v mikroekonomski teoriji kot »proizvajalec«, ki deluje v okolju omejenih informacij (Jondrow, 2014, str. 3-5). Zmotno je splošno prepričanje, da je kvantitativna analiza ${ }^{6}$ pri vojaškem načrtovanju bistveni element ekonomske analize. Izračuni, ki temeljijo na kvantitativni analizi, niso nujno uporabni, ampak je to odvisno od vrste problema in koliko o njem vemo. Najpomembnejše so primerjave med različnimi alternativami s stališča uresničitve ciljev in stroškov, ki jih vključujejo. Elementi vojaškega problema pri ekonomski analizi lahko vključujejo napredno matematiko, zmogljivo programsko opremo ali fizično/logično razmišljanje (Quade, idr., 2014, str. 35).

Ekonomska analiza zajema naslednje elemente načrtovanja:

1) Definiranje ciljev. Definiramo, kakšen je namen/cilj vojaške organizacije, katerega lahko dosežemo z enotami, opremo, projekti in taktiko. Izbira pravih ciljev pri vsakem odločanju je pomembna, da dosežemo optimum in učinkovitost.

2) Alternative. Alternative so različni vojaški sistemi (del sistemske analize), ki vključujejo osebje, opremo in taktiko za doseganje cilja.

3) Stroški oziroma uporaba virov. Vsaka alternativna metoda za dosego cilja vključuje stroške za uporabo določenih virov.

\footnotetext{
Brez kvantitativne analize pridemo v stanje nevednosti in intuicije, ker princip deluje na številkah, logiki in usmerjenosti $v$ cilj.
} 
4) Modeli. Modeli ${ }^{7}$ so razumljiva abstraktna predstavitev realnosti, s katerimi zaznamo relacije in korelacije $\mathrm{v}$ resničnem okolju in s katerimi manipuliramo oziroma predvidevamo druge (npr. model letala, določene relacije med objekti ali matematični modeli). V sistemskem analitičnem modelu se prikazujejo odnosi med vnosi podatkov, rezultati, viri in cilji za vsak primerljiv sistem, da lahko predvidimo posledice in izbiro enega sistema pred drugim.

5) Kriteriji. Izbira pravega kriterija je pogost problem v sistemski analizi. V večini vojaških sistemskih analiz moramo biti zadovoljni s približki idealnim kriterijem, da na primer sistem A ni optimalen, vendar je boljši kot predlagana sistema B in C (Quade, idr., 2014, str. 35-37).

\subsection{Kreativnost in kritičnost}

Skoraj v vseh funkcijah in procesih, ne glede na to, ali gre za vojaško oziroma civilno ozadje, umeščenost obeh v organizacijski strukturi (po vertikali ali horizontali), se praviloma vedno srečujemo s kritičnim oziroma logičnim razmišljanjem in kreativnostjo. Pojem kritičnega razmišljanja razumemo kot pravilen način pri sledenju in pridobivanju pomembnih in zanesljivih vedenj oziroma znanj o svetu, ki nas obkroža. Sicer pa to pomeni tudi razumsko, samokritično (refleksivno), odgovorno in spretno razmišljanje, ki je predvsem osredotočeno na odločanje, v kaj verjeti ali kaj storiti. Samo s kritičnim razmišljanjem lahko postavljamo ustrezna (prava) vprašanja, zbiramo pomembne informacije, jih učinkovito in kreativno razvrščamo, razumsko sklepamo ter pridemo do zanesljivih in zaupanja vrednih zaključkov, ki so pogoj za uspešno delovanje. Ni odločitve ali aktivnosti, pri čemer predhodno ne bi izvajali analize ter na podlagi kritičnega razmišljanja s pomočjo kreativnosti razvijali ali generirali nove ideje, pristope in koncepte (kognitivni inženiring). Veščine kritičnega razmišljanja so pomemben dejavnik (generator) na vseh področjih posameznikovega ali organizacijskega strokovnega in praktičnega delovanja, še posebno na področjih, na katerih je treba oblikovati koncepte (modelirati) in predstaviti ideje, analizirati in reševati probleme ter ne nazadnje tudi sprejeti odločitev (Lau, 2015).

\subsection{Prednostni pristop}

Prednostni pristop kot eden izmed številnih postopkov, ki se mu v procesu odločanja ne moremo izogniti, ne glede na to, ali govorimo o vojaškem načrtovanju ali o drugih podobnih javnofinančnih aktivnostih, pogostokrat naleti na zelo kritičen odnos tako uporabnikov - pripravljavcev predlogov (analitikov) kot tudi naročnikov odločevalcev. Da bi olajšali proces izbire v fazi priprave predloga ali sprejem končne odločitve po predstavitvi analiziranih možnosti pri porabi določenih finančnih virov, se želena sredstva nabave razvrščajo v skladu s predhodno že določenimi prioritetami potreb ali zahtev. To je izraženo v obliki seznama, v katerem so vsi predmeti nabave (samo tisti, ki si jih lahko privoščimo) razporejeni v skladu s pomembnostjo tako, da je izražena prednostna lestvica. Bolj je izražena pomembnost, na višjem mestu je predmet,

Modeli so le slikovna/fotografska reprodukcija realnosti, pri čemer je pomembno, da v največjem mogočem obsegu merjenje rezultata odraža dejanske rezultate realnega sistema, ki ga modeliramo. 
in sicer glede na njegove kriterije, zahteve in potrebe. V praksi so lahko tovrstni seznami pogostokrat zelo obsežni in vsebujejo nepregledno množico razvrščenih podatkov.

Način uporabe prednostnega pristopa z oblikovanjem seznamov ni popolnoma jasen. Torej, v kolikšnem obsegu in kdaj nameniti razpoložljive finančne vire za vsako sredstvo, zapisano na prednostnem seznamu, je res izziv ali celo problem. Ne glede na vse pa želimo, da se pri razvrščanju finančnih virov dodana vrednost na enak način odraža oziroma pozna pri nabavi vseh sredstev, ne glede na to, kakšen in kolikšen je njihov namen ali pomen. Tako zagotovimo, da so nam enako pomembni stroški izdatkov vseh nakupov (povzeto po izročkih DRMI).

Primer Slovenije: TD Young (2016, str. 32) ugotavlja: »Primer prakse centralnovodenega in ne delegiranega finančnega odločanja do poveljnikov nižjih ravni (katerih odgovornost je proces izgradnje obrambnih zmogljivosti) povzroča, da nikoli ne bodo mogli doseči lastnega profesionalnega potenciala v celoti, kar se bo posledično preneslo $v$ prihodnost, ko bodo zasedali višje položaje v vojaški strukturi. Prav tako je pomembna potreba po prilagoditvi koncepta, kjer je uporaba stroškovnih prioritet osnovno vodilo pri obrambnem načrtovanju.«

Razumevanje prednostne naloge izhaja iz smiselne trditve, da se morajo najprej realizirati tiste stvari, ki so prednostne (izhajajoče iz prednostnih potreb ali zahtev). Pomembno je, da upoštevamo uporabo minimalnega povečanja razpoložljivih sredstev ali časa. V situacijah, ko se odločamo o uporabi/investiranju/vlaganju dodatnih finančnih sredstev ali časa, si je vedno smiselno zastaviti vprašanje »Kaj je v danem trenutku najbolj nujno (prva prioriteta)?«. Ko se odločamo, kako uporabiti razpoložljive vire v naslednjem obdobju, se navadno spoprijemamo s problemom njihovega razreza, ne pa z določanjem prioritet, kar nam ne pomaga rešiti omenjene dileme. Zato je pomembno, da se pri oblikovanju obrambne politike/strategije in izbiri oborožitvenega sistema odločimo, koliko naporov in virov naj bi namenili oziroma porabili za vsako postavko posebej (poglobljena analiza). Prednostni pristop ne rešuje nastalih težav z dodeljevanjem virov. Nasprotno, tako lahko postanemo celo ujetniki pri sprejemanju oziroma implementaciji zgrešenih politik/strategij, ki pa lahko zaznamujejo večletno obdobje v prihodnosti (povzeto po izročkih DRMI).

\subsection{Kvantitativna analiza}

Da bi se pri odločanju pri obrambnem načrtovanju pogosteje uporabljala kvantitativna analiza $^{8}$, navajamo dva primera kvantitete pri odločanju za izbiro radarja za potrebe zračne obrambe in izbire radijske postaje.

\footnotetext{
8 Razlike oziroma prednosti kvantitativnih analiz pred kvalitativnimi analizami se kažejo že v vhodnih podatkih (besedila, slike, intervjuji), saj kvalitativne metode niso merljive oziroma jih težko prikažemo v številkah. Kvantitativne metode so torej bolj uporabne pri analiziranju podatkov za načrtovanje in temeljijo na statističnih metodah in matematiki. Seveda je kombinacija obeh analiz najboljša v procesu odločanja, vendar je pri načrtovanju treba dati prednost kvantitativni analizi zaradi večje zanesljivosti in objektivnosti. Razlogi za odločanje na kvantitativni način so lažja formulacija problemov odločanja, odločitve v negotovosti, podatkovna analiza, preverjanje predpostavk, ocena tveganj in predvidevanje.
} 
Primer problema 1: Kateri radar bomo izbrali, da bo najbolj učinkovit? Določimo parametre, navedene v hierarhični shemi spodaj (Kako pomembno?). Doseči želimo stoodstotno učinkovitost, vendar se moramo osredotočiti na to, kateri parametri so za nas najpomembnejši, in jih ovrednotiti. V primeru bomo prikazali odstotne točke, ki pa so le prikaz odločanja na podlagi lastne izbire?

Slika 3:

Shematični prikaz učinkovitosti radarja (povzeto po izročkih DRMI)

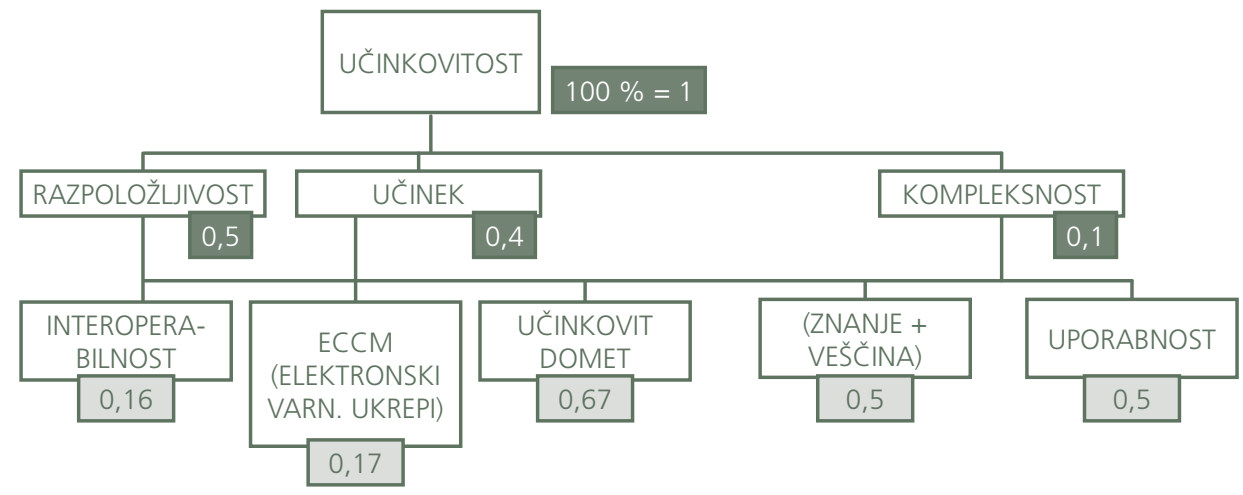

Primer vrednotenja posameznega atributa: Domet radijske postaje (Koliko je dovolj?)

Izračun:

- Ni dovolj dometa $\leq 1 \mathrm{~km}$.

- Dovolj dometa $\geq 6 \mathrm{~km}$.

$=\frac{\text { mera }-\boldsymbol{n i} \text { dovolj }}{\text { dovolj }- \text { ni dovolj }}=(4-1) /(6-1)=\mathbf{0 , 6}(\text { mera učinkovitosti na razdalji } 4 \mathrm{~km})^{10}$

9 Pomembno je, da razumemo, da je stroškovna učinkovitost sestavljena iz merjenja stroškov kot vhodnih podatkov in učinkovitosti kot izhodnih podatkov. Razmišljati moramo o stroškovni učinkovitosti, o tem, kaj je prevladujoče, kaj je dominantno in kaj je učinkovito za obrambni sistem. Vedno iščemo optimalno rešitev med danimi predpostavkami (parametri). Kompleksnost je na primer v tem primeru »točkovana « vrednostjo 0,1, lahko bi bila tudi 0,2 in bi posledično zmanjševali učinek in razpoložljivost. Osnovni vprašanji, ki si jih moramo postaviti, sta, koliko je dovolj in koliko je to pomembno za načrtovanje (povzeto po izročkih DRMI)?

${ }^{10}$ Rezultat učinkovitosti dometa radijske postaje na razdalji $4 \mathrm{~km}$ glede parametrov ni dovolj dometa oziroma je dovolj dometa, bi bil za nas lahko optimalen. Takšna odločitev se lahko uporablja glede na konfiguracijo terena ali potrebe neke vojaške enote. 
Slika 4:

Grafični prikaz

učinkovitosti

dometa

radijske postaje

(Povzeto po

izročkih DRMI)

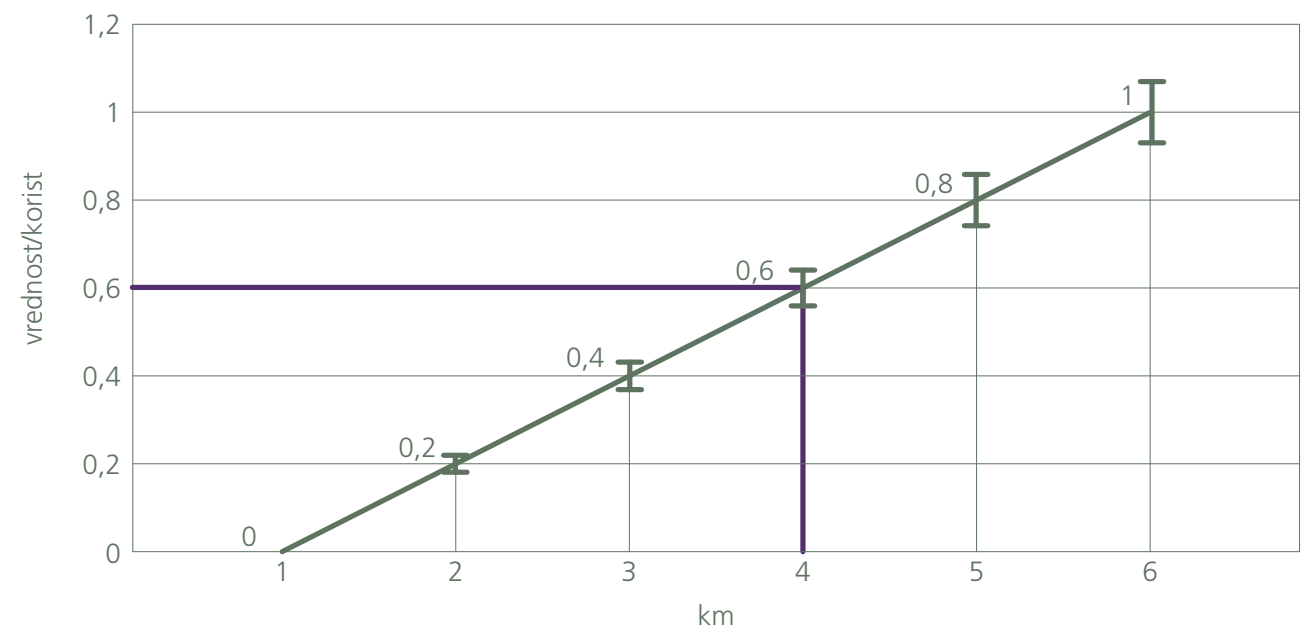

Drugi primer vrednotenja posameznega atributa: Masa radijske postaje (Koliko je dovolj?). Masa je pomemben element pri transportu na terenu. Manj mase je, bolje je.

Izračun:

- Dovolj lahka za uporabo 0,5 kg.

- Prevelika teža $10 \mathrm{~kg}$.

$=\frac{\text { mera }-\boldsymbol{n i} \text { dovolj }}{\text { dovolj }-\boldsymbol{n i} \text { dovolj }}=(8-10) /(0,5-10)=\mathbf{0 , 2 1}(\text { mera učinkovitosti pri teži } 8 \mathrm{~kg})^{11}$

Slika 5:

Grafični prikaz

učinkovitosti

mase radijske

postaje

(povzeto po izročkih DRMI)

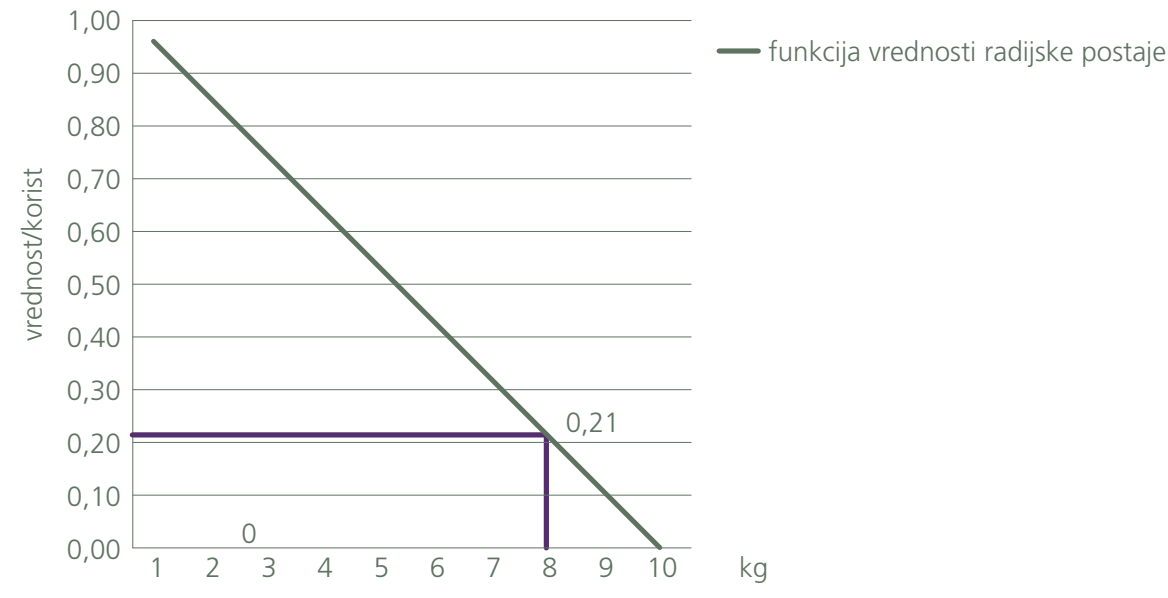

${ }^{\prime \prime}$ Rezultat je računsko prikazan z enako metodologijo kot v prvem primeru. Odločitve na podlagi teh izračunov imajo določene omejitve predvsem pri izbiri, kaj je dovolj in kaj ni dovolj. 


\subsection{Matematično analitični modeli in simulacije}

Primer metodologije kalkulacije stroškov v obrambnem sistemu temelji na šestih stroškovnih bazenih: osebje, delovanje enot, delovanje sredstev, nabava sredstev, projekti in vojne rezerve. Vsaka od naštetih stroškovnih kalkulacij ${ }^{12}$ temelji na enaki organizacijski strukturi vojske in zmožnosti enot (Papler, 2005, str. 69). Razmerja med stroški se lahko opišejo na več načinov, kar je odvisno od razpoložljivih podatkov, ki so nujno potrebni za uporabo matematično analitičnih modelov.

\subsubsection{Matematični modeli}

Poznamo več vrst matematično analitičnih modelov ${ }^{13}$, ki nam lahko pomagajo pri načrtovanju virov. V nadaljevanju bomo na kratko povzeli samo najpogostejše primere pri uporabi za načrtovanje.

1. Poissonova porazdelitev $\mathrm{P}(\lambda)$ kot oblika verjetnostne porazdelitve se v Excelu na finančnem področju opredeljuje kot napoved števila dogodkov za določeno obdobje: preštejemo na primer število vojaških letal, ki v 15 minutah pridejo na točko delovanja. Vsota posameznih verjetnosti $\mathrm{P}(\mathrm{x})$ mora biti enaka 1. Pri Poissonovi porazdelitvi so dogodki naključni in neodvisni.
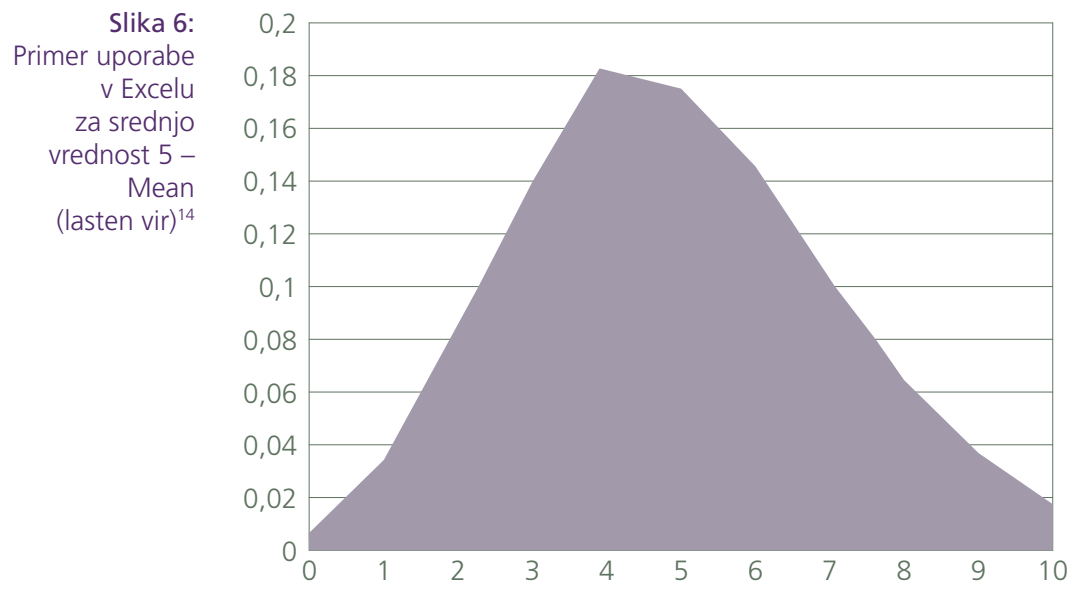

\begin{tabular}{|c|c|}
\hline$x$ & $P(X)$ \\
\hline 0 & 0,0067 \\
\hline 1 & 0,0337 \\
\hline 2 & 0,0842 \\
\hline 3 & 0,1404 \\
\hline 4 & 0,1755 \\
\hline 5 & 0,1755 \\
\hline 6 & 0,1462 \\
\hline 7 & 0,1044 \\
\hline 8 & 0,0653 \\
\hline 9 & 0,0368 \\
\hline 10 & 0,0181 \\
\hline
\end{tabular}

Test verjetnosti x s povprečjem

12 Agregirane v obliki vojaških zvrsti, proračunskih postavk in poslanstev.

${ }_{13}$ Poissonova porazdelitev, Zaporedje neodvisnih poskusov (Bernoullijevo zaporedje), binomska porazdelitev, eksponentna porazdelitev, normalna ali Gaussova porazdelitev, beta model, Erlang, logaritemsko normalna porazdelitev, zbirna funkcija verjetnosti, Pareto analiza, logistični model, porazdelitev gama, t-test, analiza sedanje vrednosti itn.

${ }_{14}$ Poleg časovnega intervala lahko uporabljamo takšno obliko verjetnostne porazdelitve v MS Excelu tudi pri razdalji, površini ali prostornini. V Excelu za računanje verjetnosti $P(A 1, A 2, T R U E)$ uporabljamo POISSON. DIST kot kumulativno verjetnost $z$ določenimi argumenti v celicah A1 in A2. Kot funkcijo Poissonove masne verjetnosti pa uporabljamo namesto TRUE - FALSE. x je število dogodkov, Mean je pričakovana številska vrednost in na koncu še logična vrednost. Za verjetnost $x$ dogodkov pri vojaških letalih na točki delovanja lahko ugotovimo, da letala ne pridejo na točko delovanja enakomerno, temveč precej slučajno. Na abscisni osi torej lahko merimo število prihodov vojaških letal na točko delovanja in na ordinatni osi njihovo verjetnost. 
2. Zaporedje neodvisnih poskusov je preračunavanje, kolikšna je verjetnost, da se v $n$ zaporednih poskusih zgodi dogodek A natanko k-krat. Najprej se zgodi k-krat $\operatorname{dogodek} \mathrm{A}$ in nato $\mathrm{v}$ preostalih $(\mathrm{n}-\mathrm{k})$ poskusih nasprotni dogodek $\tilde{\mathrm{A}}$ :

$$
P\left(\bigcap_{i=1}^{k}\left(X_{i}=A\right)\right) \cap \bigcap_{i=k+1}^{n}\left(X_{i}=\tilde{\mathrm{A}}\right)=\prod_{i=1}^{k} P(A) * \prod_{i=k+1}^{n} P(\tilde{\mathrm{A}})=P^{k} * q^{n-k} .
$$

Verjetnost dogodkov glede na različne načine pri $n$ in $k$ poskusih je nezdružljivo med seboj, zato je verjetnost enega dogodka enaka t. i. Bernoullijevemu obrazcu:

$\left.P_{n}(k)=\left(\begin{array}{l}n \\ k\end{array}\right) p^{k}(1-p)\right)^{n-k}($ Jurišić in Batagelj, 2007, str. 46).

3. Binomska porazdelitev

Binomska porazdelitev ima zalogo vrednosti $\{0,1, \ldots, n\}$ in verjetnosti, ki jih računamo po Bernoullijevem obrazcu. Simetrična je samo takrat, ko je p = 0,5. Pri binomski porazdelitvi nas zanimata dva mogoča izida: dogodek (DA) ali dogodek (NE). Verjetnost uspeha ostane vedno na isti ravni preizkusa. Vsi preizkusi so neodvisni. V praksi velikokrat izračunavamo pogostost nevarnosti terorističnega napada.

4. Analiza sedanje vrednosti

$\mathrm{S}$ to metodo preračunavamo sedanje vrednosti različnih alternativ. Ta analitična metoda omogoča uporabo pričakovane »najboljše« uporabe sredstev. Razlike so pri nominalni (+inflacija) in realni obrestni meri.

$P_{n}=S(1+r)^{n} \Rightarrow S=\frac{P_{n}}{(1+r)^{n}}$

$\mathrm{P}_{\mathrm{n}}=$ prihodnja vrednost $\mathrm{v}$ časovnem obdobju $\mathrm{n}$

$\mathrm{S}=$ sedanja vrednost

$\mathrm{r}=$ obrestna mera

$\mathrm{n}=$ število obdobij (povzeto po izročkih DRMI)

Primer:

$\mathrm{P}_{\mathrm{n}}=1000 €$

$\mathrm{r}=10 \%$

$\mathrm{n}=5$ let (srednjeročno plansko obdobje)

$\mathrm{S}=1.000(1+0.1)^{5}=621$

$$
P_{n}=S(1+0.1)^{5} \Rightarrow S=1.000 \div(1+0.1)^{5}
$$

Sedanja vrednost (leto 0) v petletnem obdobju je 621 evrov. Razlika je očitna in vrednost denarja se z leti spreminja, zato lahko pri proračunskem načrtovanju veliko prihranimo. 


\subsubsection{Simulacije}

Za kakovostno strateško odločanje se moramo najprej vprašati, kaj so prednosti in pomanjkljivosti simulacij/modeliranja, preden se odločimo za uporabo v načrtovanju virov. Še preden začnemo proces načrtovanja, je treba izvesti strateško preigravanje (Strategic War Gaming) in vse vpletene akterje postaviti na skupni imenovalec, kar je princip strateškega razmišljanja. Pomembna je tudi odločitev, koliko časa smo pripravljeni nameniti simulacijam in koliko različnih vrst simulacij želimo izvesti.

\begin{tabular}{c|l|l|}
\cline { 2 - 3 } $\begin{array}{c}\text { Tabela 2: } \\
\text { Priprava } \\
\text { predloga za } \\
\text { odločanje } \\
\text { (simulacija/ } \\
\text { preigravanje). }\end{array}$ & POMANJKLJIVOSTI & PREDNOSTI \\
\cline { 2 - 3 } & Samo orodje za analizo ne bo generiralo rešitev. & Ko je dejansko opazovanje predrago. \\
\cline { 2 - 3 } & Lahko zahteva dodatne stroške. & Dovoljuje zgostitev časa. \\
\cline { 2 - 3 } & $\begin{array}{l}\text { Lahko pride do situacije, da modeli in eksperimenti } \\
\text { niso nič boljši od predpostavk s podprtimi podatki. }\end{array}$ & Dovoljuje senzitivno analizo. \\
\cline { 2 - 3 } & & Dovoljuje kontroliran eksperiment. \\
\cline { 2 - 3 } & & Učinkovito orodje za usposabljanje. \\
\hline
\end{tabular}

Sledi preverjanje veljavnosti modela kot grobe slike realnosti. Preverjanje veljavnosti modela je nujno, če je uporabljeno analitično orodje dovolj dobro za predstavljanje realnosti. Najbolj primeren preizkus izvajamo s pomočjo analize občutljivosti in verjetnosti (Papler, 2005, str. 75).

Aplikacije za simulacijsko modeliranje so na različnih ravneh in če prakticiramo od zgoraj navzdol, se najprej ukvarjamo s t. i. popisnim menedžmentom, razporejanjem virov, razvrščanjem virov, načrtovanjem, različnimi napovedmi in vojnim preigravanjem. Simulacija kot orodje za modeliranje vedno deluje na treh ravneh:

1. uporaba matematičnih zakonitosti,

2. verjetnostna distribucija realnih dogodkov,

3. naključna števila, ki predstavljajo realne dogodke.

V sodobnem simuliranju velikokrat uporabljamo metodo Monte Carlo ${ }^{15}$, ki je tehnika vzorčenja (funkcija verjetnosti) in temelji na računalniškem generiranju naključnih števil.

\footnotetext{
${ }^{15}$ Monte Carlo so numerične simulacijske metode ali algoritmi, s katerimi si pomagamo pri izračunavanju vrednosti investicij na področju finančnega načrtovanja. Naključno generiranje števil v vedno krajšem času in njihova razpršenost nam pokažeta, kako se moramo odločiti v dani situaciji.
} 


\section{SPREJEMANJE ODLOČITEV V RAZMERAH NEGOTOVOSTI (UNCERTAINTY)}

Verjetnost je najboljša metoda za merjenje negotovosti. Stroški vojaškega sistema V prihodnosti in število umrlih vojakov je skoraj vedno rezultat negotovosti in se prevesi v nesprejemljivo tveganje. Z definiranjem sprejemljivega tveganja ugotavljamo, da je odvisen od verjetnosti. Verjetnost je število med 0 in $1(0 \leq \mathrm{V}(\operatorname{dogodka}) \leq 1)$, ki izkazuje možnost pojavljanja dogodka ${ }^{16}$. V praksi se uporablja za bolj kompleksne dogodke v vojaškem smislu (vojna DA ali NE) in vojaški proračun se na primer poveča za 3 odstotke. Za shematski prikaz se uporablja t. i. Probability Tree (Shematski prikaz testa verjetnosti), na katerem so upodobljeni dogodki in verjetnosti, izražene s koeficientom, kar je prikazano v nadaljevanju (Mackenzie, 2015, str. 1-5). Pri teh shematskih modelih je treba stremeti k poenostavljenemu prikazu, vendar ne sme izničiti razmerij in soodvisnosti vrednosti pojavov.

Predpostavke (vhodni podatki) za naslednje leto:

$\mathrm{V}^{17}($ vojna $)=0,1$

$\mathrm{V}(\mathrm{mir})=0,9$

$\mathrm{V}($ rast proračuna za $>3 \%)=0,25$

$\mathrm{V}$ (proračun med $\pm 3 \%$ ) $=0,5$

$\mathrm{V}($ zmanjšanje proračuna za $>3 \%)=0,25$

Slika 7:

Shematski test verjetnosti (Probability

Tree) z

neodvisno spremenljivko (Mackenzie, 2015, str. 2)

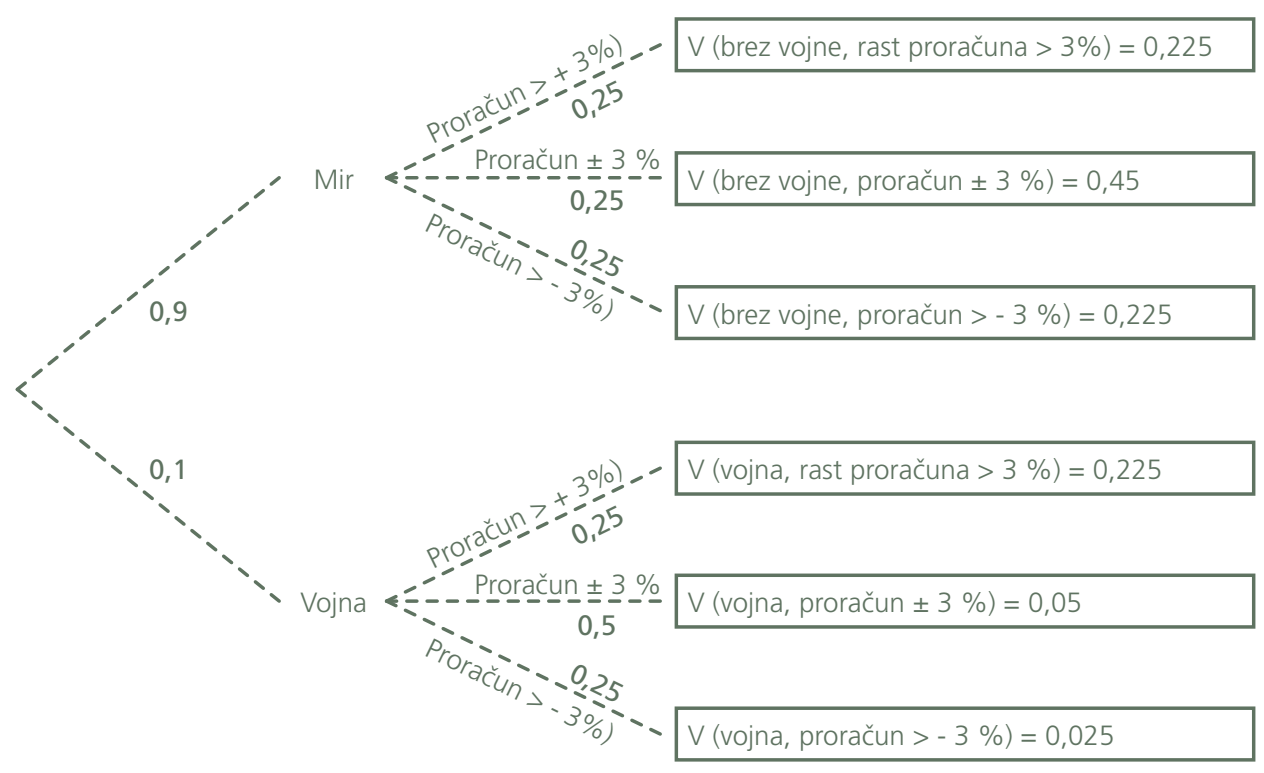

${ }^{16} \check{C}$ e poenostavimo, pri dvojnem metanju kovanca se lahko pojavijo štirje enostavni dogodki: glava - glava, glava - število, število - glava in število - število (Mackenzie, 2015, str. 1).

${ }_{17} V=$ Verjetnost. 
Če sta dva dogodka neodvisna, je združena verjetnost izračunana iz posameznih verjetnosti. Matematično gledano, če sta $\mathrm{A}$ in $\mathrm{B}$ neodvisna, je $\mathrm{V}(\mathrm{A}, \mathrm{B})=\mathrm{V}(\mathrm{A})$ * V (B) (Mackenzie, 2015, str. 3). Če se pojavi verjetnost vojne, neodvisna od obrambnega proračuna, obstaja tudi način prikazovanja z odvisno spremenljivko. Matematično se potem spreminja način preračunavanja, če je na primer $V(B \backslash A)$ odvisna spremenljivka dogodka B pogoj za pojav dogodka A. Verjetnost dveh odvisnih dogodkov se preračunava z množenjem odvisne verjetnosti enega dogodka, preračunava se $\operatorname{kot} \mathrm{V}(\mathrm{A}, \mathrm{B})=\mathrm{V}(\mathrm{B} \backslash \mathrm{A}) * \mathrm{~V}(\mathrm{~A})$ ali enakovredno $\mathrm{V}(\mathrm{A}, \mathrm{B})=\mathrm{V}(\mathrm{A} \backslash \mathrm{B})$ * $\mathrm{V}$ (B). Ta formula za združene verjetnosti ostaja veljavna, če sta A in B neodvisni spremenljivki, ker $\mathrm{V}(\mathrm{B} \backslash \mathrm{A})=\mathrm{V}(\mathrm{B})$ in $\mathrm{V}(\mathrm{A} \backslash \mathrm{B})=\mathrm{V}(\mathrm{A})$, kot je upodobljeno na sliki 7 (Mackenzie, 2015, str. 4-5).

Sklep Odločitev v pogojih »neznanega« se pogosto pojavlja pri finančnem načrtovanju. Večkrat se nam v obrambnem sistemu lahko zgodi, da pri izbiri sredstev za kosovni načrt vsakokrat prihajamo do nepreverjenih odločitev (ni analitične podlage), ali pa celo pride do strokovnega zanemarjanja in se nam vsiljujejo rešitve, ki ne odražajo potreb sistema, temveč določenih interesnih skupin. Matematične modele in izračune moramo uporabljati pri kompleksnih vojaških rešitvah, pri manj kompleksnih je velikokrat potrebna oziroma bolj smiselna le logična presoja.

$\mathrm{Na}$ področju obrambnega načrtovanja moramo v RS spremeniti pristop oziroma metodologijo. S strateškim preigravanjem zajamemo večino osnovnih konceptov, vpletenih v proces modernega obrambnega načrtovanja, kot so stroškovne priložnosti, kvantitativne analize, alternative oziroma možnosti v procesu odločanja, marginalni stroški, analiza stroškov in koristi in z razvijanjem konceptualnega okvirja, v katerem poskušamo na najbolj optimalen in učinkovit način razporediti že tako omejene vire za potrebe nacionalne varnosti.

Analitične tehnike, predstavljene v glavnem delu, bi se lahko integrirale in upoštevale pri pripravi Srednjeročnega obrambnega programa Republike Slovenije (SOPR), in sicer v delu, ki obravnava nabave, plačila in investicije, ter pri načrtovanju izdatkov za program vojaške obrambe. Gre za timski izdelek obrambnih načrtovalcev in strokovnjakov iz sektorja za finance. Nadgradnja oziroma dopolnitev obrambnih načrtov bi bila smiselna $\mathrm{z}$ boljšo konkretizacijo opreme za vsaj eno raven nižje, in sicer uporaba metodologije prednostnega pristopa do razporejanja virov (razvrščanje po lestvicah). Pri obrambnih sistemih večje vrednosti je vedno treba prikazati rezultate tabelarno, shematsko in grafično. Na podlagi teh prikazov se ugotavljajo odstopanja od razpoložljivih virov.

Del načrtovanih izdatkov za program vojaške obrambe, in sicer za raziskave in razvoj, bi bilo treba povezati z razvojnim delom državnega proračuna, v katerem so nacionalni razvojni programi. Tako bi se zagotovili finančni viri za dano petletno obdobje in ublažile posledice morebitnih rezov ter podvajanj v razvojnem smislu na nacionalni ravni. 
Na področju stroškovne analize je treba vsebine razporejati v tri sklope (1) Stroški raziskav in razvoja, (2) Investicijski stroški in (3) Operativni stroški. Vsaka drugačna delitev je nepregledna, nepovezljiva in nesmiselna, saj bi pri nadaljnjih izračunih prihajalo do napačnih predpostavk in anomalij.

Napačni sklepi glede načrtovanja ali razporejanja virov ne zagotavljajo uspeha za promoviranje zmogljivosti in učinkovitosti. Analitična orodja in pravila odločanja imajo pomembno vlogo pri razporeditvi virov znotraj različnih alternativ, ki pa so vedno na razpolago (iščemo najbolj ustrezno, torej ni napačnih odločitev). V tem prispevku smo prikazali modele, metode in splošen (grob) okvir za obrambno načrtovanje $\mathrm{z}$ objektivnimi in zanesljivimi metodami, da se pri porabi obrambnih finančnih sredstev zmanjšujejo dejavniki tveganja. Analitično okolje za obrambne/ vojaške odločevalce postaja sodobna/stalna praksa reševanja upravljanja virov.

\section{Literatura}

1. Joint Analysis Handbook $-4^{\text {th }}$ Edition (NATO Publication), February 2016. Joint Analysis and Lessons Learned Centre, Monsanto-Portugal.

2. Jondrow J., 2014. Military Readiness, Budget Programming and Economic Theory. CNA Analysis and Solutions. Department of Defense, USA.

3. Jurišić A. in Batagelj V., 2007. Verjetnostni račun in Statistika, http://lkrv.fri.uni-lj. si/ ajurisic/vis07/folije/vs03.pdf, 17. 7. 2017.

4. Kahneman D., Thinking Fast and Slow, 2011. Farrar, Straus and Giroux. New York, USA.

5. Lau, Joe Y. F., 2015. An Introduction of Critical Thinking and Creativity. Wiley. New Jersey, USA.

6. Mackenzie A. C., 2015. A Review of Probability and Statistics. DRMI. Monterey, Naval Postgraduate School, USA.

7. Mehta A., 2016. Poland wants to play in Franco-German Tank Program; Defense News. Washington, USA.

8. http://www.defensenews.com/story/defense/policy-budget/industry/2016/08/03/polandwants-play-franco-german-tank-program/87929202/, 22. 7. 2017.

9. Melese F., et al., 2015. Military Cost-Benefit Analysis: Theory and Practice. Routledge Studies in Defence and Peace Economics. Monterey, USA.

10. Mikuž I. in Šavc P., 2011. Razvoj Slovenske vojske v drugem dvajsetletju njenega obstoja. Sodobni vojaški izzivi, št. 13. Generalštab SV, Ljubljana, Slovenija.

11. Papler P., 2005. Računovodsko predračunavanje s simulacijskim modelom za odločanje o načrtih Slovenske vojske, magistrsko delo, Ekonomska Fakulteta, Ljubljana, Slovenija.

12. Quade, E. S. idr., 2014. Readings in Defense Resource Management-RDRM. Pearsons Learning Solutions, Boston, USA.

13. Sintern W., 2017. European Defence Matters. McKinsey Analysis on the Benefits of EU Defence cooperation. European Defence Agency. Vol. 13, str. 30-33.

14. Stewart G. M. and Mueller J., 2013. Terrorism Risks and Cost-Benefit Analysis of Aviation Security; Risk Analysis, Vol. 33, No. 5.

15. Young T. D., 2016. The Challenge of Defense Reform in Central/Eastern Europe, with reference to Slovenia. Sodobni vojaški izzivi, št. 4. Generalštab SV, Ljubljana, Slovenija. 